\title{
The choice of pseudoscientific therapies as an alternative to scientific medicine
}

\author{
Sergi Cortiñas Rovira \\ Universitat Pompeu Fabra (Spain) - sergi.cortinas@upf.edu \\ Valentina Raffio \\ Universitat Pompeu Fabra (Spain) - valentina.raffio01@estudiant.upf.edu
}

\begin{abstract}
During the last decades, there has been an increasing interest in the analysis of a potentially dangerous phenomenon for the public health: pseudoscience. It can be defined as the set of false knowledge that attempts to resemble science even though it is not. Nowadays there are many who opt for these therapies not scientifically endorsed to solve their health problems. This situation is increased for risk patients or chronic diseases, who come to this type of therapies as a last resort. In these cases, the choice between science and pseudoscience can become a matter of life or death. Through qualitative and quantitative research techniques, we analyze the reasons why patients choose pseudoscience instead of conventional and scientific medicine. The data obtained from this research reveal that in extreme situations patients value most the human contact with the therapist that the validity of the therapy itself. This factor, coupled with the precariousness of the health system, generates a dynamic in which pseudosciences gain ground over scientific medicine. According to the experts interviewed, this phenomenon is increasing and may represent a danger to public health. This research reveals the possible causes and consequences of this phenomenon from the point of view of more than 60 professionals of the Spanish scientific community and 30 patients who have used both disciplines. The results obtained indicate that this situation is intensified due to the inaction of the competent institutions and the lack of regulation.
\end{abstract}

Keywords:Pseudoscience, scientific medicine, scientific community, public health

\section{Introduction}

Nowadays, the era in which we live has been defined by many experts as a stage of absolute dominance of reason and technology. Two factors that substantially influence the development and evolution of our civilization. Manuel Castells, sociologist and economist, defined this period of the human history under the concept of Information Society. This conceit refers to an era characterized by a major diffusion of knowledge and, consequently, an improvement in the quality of life of the citizens (Castells, 1996). Paradoxically, there is a general perception among the experts that the more information society has, the more misinformed people are. In recent years, there has been a clear increase of theories, thoughts and ideologies which are based on falsehoods and can be considered potentially dangerous to public health: pseudosciences (Jensen \& Hurley, 2012).

The definition of the pseudoscience phenomenon raises a lot of controversy because of the variety of areas between there falsely scientific ideas are manifested. History of science investigators consider that this phenomenon can take place in a wide range of sectors such as history, psychology, technology and medicine (Bunge, 2013; Hansoon, 1997; Shermer, 1997). In all these areas, there have been cases of pseudoscientific schools that generate unfounded knowledge. This is the case, for example, of psychoanalysis, astrology, alchemy or holocaust denial (Eaglestone, 2001; Bunge, 2013). Traditionally, pseudo (false) science (knowledge) has been conceived as a concept antagonistic to science. From the point of view of the positivist philosophical theory, the pseudosciences can be defined as mimetic disciplines that appear to be science without actually being it (Gordin, 2012). In this process of inverse creation, these disciplines take advantage of certain scientific paradigms to gain more credibility.

Among all this variety of false knowledge, there is a specific area that generates a lot of concern among the experts: the rise of alternative therapies. The expansion of pseudoscience in the medical field can be a determinant risk factor for public health (Chang, 2015). Unlike other areas, the spread of false knowledge in the health sector can become a matter of life or death. For example, the use or not of vaccines in infants can determine not only the survival of the individual but it also can affect (and harm) to its nearest circle (Lewandowsky \& Oberauer, 2016). In this context, the scientific community is a fundamental key for the delimitation of the phenomenon and for its discrediting versus the public opinion. More specifically, the medical sector represents one of the main actors in the preservation of values linked to public health since they can be considered as the main disseminators of medical knowledge among the population.

Faced with this dichotomy between information, disinformation and beliefs, the Spanish medical community has been very affected by the rise of pseudo-sciences. In order to understand this phenomenon, it must be taken into account that today the medical community is more exposed than ever to socio-political fluctuations (Martínez, Smith, Llop-Gironés, Vergara, \& Benach, 2016). First of all, the economic crisis 
has led to cuts in Spanish public health and an intense process of privatization of the sector. Secondly, as a result of the above, the majority of the sanitary personnel have been acquiring more workload and pressure in their routines. The most direct consequences are the progressive increase of working hours, increasing shifts, a greater ratio of patients attended, reduction of salaries, continued cuts in material between others. Thirdly, this disintegration of the health sector, both from the point of view of structures and staff, has directly affected the patient's care. The saturation of health centers has resulted in increasingly short visits (in the primary care) and longer waiting lists (in the specialized care). This process, in the long run, may have led to the transfer of patients from scientific disciplines to pseudosciences (Martínez et al., 2016).

The main objective of this research is to analyze the leakage of patients from the conventional health system to pseudoscientific therapies. More specifically, this research has tried to explain the reasons why patients decide to fall into the hands of pseudoscience to recover. Due to the increasing expansion of pseudosciences, this issue can now be considered one of the most important challenges for public health. Beyond a mere object of academic study, understanding the phenomenon of pseudoscience is a priority for our society.

\section{Literature review}

Throughout history, scientific thought has been developing an increasingly detailed knowledge of the world. In its origins, science included a large amount of disciplines related to natural philosophy (the philosophical study of nature and the physical universe) which approach the study and comprehension of the Earth environment from different points of view. Disciplines such as physics, mathematics, or alchemy attempted to offer a coherent and solid explanation of the world (Ormerod, 2009). The Enlightenment represented a decisive moment for the definition of science that we have today. Beginning with Scientific Revolution, intellectual movements emerged to delimit empirical scientific knowledge from the one that was merely speculative. Thinkers such as Francis Bacon, René Descartes, and David Hume tackled the problem from a philosophical perspective, trying to create schemas to define what was science (Harman, 1987). The result of this process was the creation, establishment and application of the scientific method. From this moment on, the disciplines that were dealing with the knowledge of natural philosophy were classified as scientific or pseudo-scientific depending on whether or not they followed this methodology. From this point of view, science and pseudoscience could be considered as antagonistic fields of knowledge with a parallel development until the Modern age.

The epistemological definition of pseudoscience has been one of the main topics of debate in the historiography of modern science. In most cases, pseudoscience is defined as the set of disciplines that attempt to resemble science without actually use the scientific method based on research, experimentation, analysis and replicability (Gordin, 2012; Rutskij, 2013; Shermer, 2001). However, this kind of generical definitions (only based in the contrast between them) cannot explain this phenomenon in depth. Mario Bunge defines science and pseudoscience as antagonistic fields of knowledge. Whereas science is situated in the field of research knowledge, pseudoscience belongs to the field of beliefs alongside ideologies and religions. In this sense, science is characterized as a "field of research whose specific background is equal to the totality of scientific knowledge accumulated in all particular sciences" while pseudoscientific disciplines are defined by the creation of a theory that endorses them individually (Bunge, 2013).

Due to the magnitude of the phenomenon, pseudoscience has been studied from different disciplines related to human knowledge. From the point of view of medicine, particular emphasis has been placed on studies to demonstrate the ineffectiveness of some of the most prominent pseudoscientific disciplines. However, the issue has not been approached from the point of view of the patients and theirs reasons to choose one discipline or another.

\section{Methodology}

One of the neuralgic centers of the debate about the influence of pseudosciences in society is the scientific collective. Beyond its role in the health care system, this sector has also become a witness to how "false science" has been introduced in the deepest part of Spanish society, resulting in a confrontation between conventional medicine and all those therapies that call themselves alternatives. Given its importance both as an external actor and as an agent involved, the medical collective plays a fundamental role in the diffusion, denial and discredit of pseudociences as disciplines suitable for the treatment of citizens. That is why his perception of the phenomenon of pseudoscience plays a fundamental role in the evolution and penetration of them. The main topic of analysis of this study is the perception of the concept of pseudoscience and its relationship with the social demand of the same. Once this framework is established, it will also be essential to analyze the risks and effectiveness of these treatments in order to assess the degree of danger they may be for the population and the public health (Niederdeppe et al., 2013). Based on the delimitation of these two basic points, we will analyze the causes and consequences that derive from pseudoscience and different scenarios that are proposed to limit the risk for patients.

This research has been carried out using qualitative and quantitative research techniques. Firstly, through a qualitative approach, we have worked on the discourse generated by pseudo-sciences in order to obtain resonance in the face of society. Secondly, quantitative techniques have been used to account for the impact (and knowledge) of some disciplines on each of the groups. Using this triangulation of methods, it has been tried to get a broader and more comprehensive approach to social reality with the ultimate goal to compare and enrich the results obtained by each method. In order to obtain in-depth information capable of analyzing this issue from the root, there have been in-depth interviews in which attempts have been made to encourage the discussion of the different professionals (Olaz Capitán, 2016; Piñuel Raigada \& Gaitán Moya, 1995). To protect their anonymity, the sources will be cited under the initials S (+ followed by the coding number of the interview). 


\section{Results}

The demonization of medicine against the hope of the alternatives therapies

The struggle between conventional medicine and pseudosciences begins in the social and semantic construction that is built around each term. Both terms obtain benefit from existing correlations around scientific jargon such as accuracy, reliability and effectiveness. But at the moment of truth, science and pseudosciences represent totally opposite poles (Bunge, 2013). In the same vein, it should be noted that in the last ten years there has been a movement focused in the demonization of scientific medicine in favor of the most natural alternatives. Scientific medicine has been associated with chemistry and, in parallel, with adverse or harmful effects. Instead, alternative therapies have been associated with everything natural and, consequently, harmless. Given this panorama of possible advantages and risks of each discipline, there are a large number of patients who choose the pseudo-scientific alternatives to avoid any adverse effects. At this point, it should be remembered that all the judgments created around these disciplines are based on popular beliefs and not on scientific statements.

One of the main results of this research is that pseudosciences generate a climate of danger around scientific medicines to position themselves as a valid alternative. The experts interviewed affirm that this strategy (demonization of medicine) is one of the main points in favor of alternative therapies to attract followers. This strategy is based on the association of the artificial with the dangerous and the natural with the beneficial (or, in the worst case, harmless). However, experts remember that all synthetic drugs are the result of extensive studies and based on the scientific method. And it is thanks to these studies that we can know all the possible side effects of these treatments. In the case of alternative therapies, we will not be able to speak of its negative effects due to the lack of study of them. There are also cases in which the absence of these adverse effects is due to the total ineffectiveness of the therapy itself. This is the case, for example, of homeopathy. This pseudoscience does not contemplate any side effects because its "dilution principle" cannot in any case cause risk to the health of the patient.

This alternative medicine has its origin in postulates of the eighteenth century. Its theoretical basis is found in the principle of similia similibus curentur, the similar cure to the similar. In its origin, its founder Samuel Hahnemann raised that the remedy for a disease is in the substance that causes it. That is why he formulated a principle according to which by diluting the molecules that cause a disease in a millionth part, this same water could be the cure for the disease. For practical purposes, homeopathy would suggest that by diluting a million times a drop of coffee in water, this dilution could serve as a cure for insomnia. With the passage of time and the systematic application of the scientific method, Hahnemann's theories have been largely refuted to the point that nowadays this "alternative medicine" is considered as a pseudoscience. In fact, current studies suggest that there is no evidence that homeopathy is effective over placebo. A review of 110 clinical trials with homeopathic products for various ailments, published in The Lancet in 2005, showed that evidence of the clinical efficacy of these remedies was very weak compared to conventional medicines for the same conditions. Of all these trials, it was precisely the ones with the highest quality (about twenty) that showed the least effectiveness. The clinical effects considered of higher quality were, in any case, compatible with the idea that these effects are due to the placebo effect. In this same sense, it should be noted that homeopathy focuses mainly on the cure of diseases with an erratic evolution or that are solved over time. A cold, for example, is passed in a week with or without medication. Even Boiron, a leading manufacturer of homeopathic products, was forced to acknowledge that there is no evidence to explain how its drugs interact with the human organism and therefore cannot explain with certainty how they function. Due to these claims, in 2012 this company had to pay \$ 12 million to a collective of users to avoid facing a misleading advertising trial (Dantas, 2005).

In words of S28, pseudoscience takes advantage of "the false idea that alternative therapies are more innocuous, more natural and less harmful". Following with this narrative, the expert interviewed adds: "Look at the example of aspirin, a drug that comes from the root of a tree that grows in the rivers (weeping willow, also known as Salix babylonica) but it is a manufactured synthetical drug. Society has lost the conception that medicines are related to nature, even if they are. People look for the natural thinking that it will do them less damage. The arsenic is a very dangerous poison and are is completely natural. Natural and harmless are used as synonyms, but they are not."

\section{The choice of pseudosciences in times of personal crisis}

One of the main conclusions obtained through the interviews points to the pseudosciences as a deception in which patients succumb when the conventional health system fails. In this sense, many of the experts consider that alternative therapies are the choice for all those patients who do not find a satisfactory cure for their pathology through scientific medicine. This situation can be due to several factors. In the first place, there are patients with chronic pathologies for which hardly ever there is a fast, effective and lasting solution. In the case of patients with chronic bone problems, the solutions provided by the doctors should be updated during the evolution of the disease. This can become a source of frustration for those affected, who may try to look for alternatives in scientifically unsupported therapies. Secondly, there are also cases in which the treatment of the disease is not comfortable for the patient. For example, in the case of highly invasive therapies for the treatment of chronic diseases. This type of process can be highly annoying for those affected, who may come to consider the search for an alternative to solve their problems. Thirdly, there are cases where the patient's clinical condition is extremely severe and there is not much to offer. For example, patients with a terminal diagnosis to whom scientific medicine cannot offer a cure. 
In all these cases, we find a situation in which vulnerable patients succumb in extremis to pseudosciences as a last resource. In the words of S18: "People are always looking for a response that is sometimes not so easy to obtain. In these cases, science is very hard and never speculates with results or possibilities. Alternative therapies, however, are more sympathetic with the patient and give him a solution, although this is a complete fraud. A person with a terminal or a chronic illness sees that science simply gives him some negative data and alternative therapies gives them some hope. The concept of pseudoscience is very close to miracles, which are hopeful and highly improbable. In science, this kind of frauds cannot exist." In the same vein, S8 adds: "No one likes to hear certain medical prognosis and, when this happens, it is normal to try to find alternative solutions."

\section{The influence of the therapist on patient choice}

One of the most controversial points in which patients indulge in pseudoscience has much to do with the human component of the relationship with their therapist. As pointed out by different experts interviewed, it is extremely important for patients to be able to establish a relationship of trust with the specialist who attends them. That is because they need a place to talk about their illness, their worries and concerns beyond the strictly medical plane. For this, it is indispensable to have sufficient time to attend each patient in the medical consultation. However, today there are several factors that prevent these situations from occurring in conventional health centers. The massification of public health and the cuts to the sector make it impossible to create a doctor-patient relationship. This situation changes completely in the case of alternative therapies, where the relationship between therapist and patient is the basis of the discipline itself. In the vast majority of pseudoscientific disciplines, the patient has all the time necessary to talk about his problems, to be heard and to get to the bottom of the question. The mere fact of having time to talk is one of the determining factors that contribute to the success of such pseudoscientific therapies. The act of externalizing these feelings related to the illness produces relief and well-being in the patient. In S24's words, "In conventional medicine, there is a clear deficit of time, and the patient needs to express things that we often do not leave to them. It is not confessional or anything like that, but as a doctor, you have to make the patient feel that you are for him. If people see that you have empathy with them you end up explaining things that normally would not explain. Then you can understand the mental part of physical ailments". In the same vein, S2 explains: "[The patients] look for solutions to issues that have no solution. Or they are looking for quick solutions to time-consuming problems. In medicine, there are treatments that last for years and are difficult to carry. In this, pseudosciences have seen a potential market because they try to offer solutions much faster than convincing people to try them out."

This same dynamic play a fundamental role in the effectiveness of prescription drugs. In medical offices, lack of time prevents the doctor from taking the time to explain the functioning and usefulness of each medication. In these situations, the patient is totally uninformed about what will happen in his body as soon as he takes the pill. In alternative therapies, however, the therapist devotes a lot of effort to let the patient know everything that the supposed medicine will do for him. This situation gives the patient a feeling of being more informed of everything that will happen after the therapy. And this is where the power of the placebo effect comes into play.

\section{Conclusions}

During the last decades, there has been an increasing interest in the analysis of a potentially dangerous phenomenon for the public health: pseudoscience. It can be defined as the set of false knowledge that attempts to resemble science even though it is not. Nowadays there are many who opt for these therapies not scientifically endorsed to solve their health problems. This situation is increased for risk patients or chronic diseases, who come to this type of therapies as a last resort. In these cases, the choice between science and pseudoscience can become a matter of life or death. Through qualitative and quantitative research techniques, we have analyzed the reasons why patients choose pseudoscience instead of conventional and scientific medicine. The data obtained from this research reveal that in extreme situations patients value most the human contact with the therapist that the validity of the therapy itself. This factor, coupled with the precariousness of the health system, generates a dynamic in which pseudosciences gain ground over scientific medicine. According to the experts interviewed, this phenomenon is increasing and may represent a danger to public health. This research reveals the possible causes and consequences of this phenomenon.

One of the neuralgic centers of the debate about the influence of pseudosciences in society is the scientific collective. Beyond its role in the health care system, this sector has also become a witness to how "false science" has been introduced in the deepest part of Spanish society, resulting in a confrontation between conventional medicine and all those therapies that call themselves alternatives. Given its importance both as an external actor and as an agent involved, the medical collective plays a fundamental role in the diffusion, denial and discredit of pseudosciences as disciplines suitable for the treatment of citizens. That is why his perception of the phenomenon of pseudoscience plays a fundamental role in the evolution and penetration of it. The main topic of analysis of this study is the perception of the concept of pseudoscience and its relationship with the social demand of the same. Once this framework is established, it will also be essential to analyze the risks and effectiveness of these treatments in order to assess the degree of danger they may be for the population and the public health (Niederdeppe et al., 2013). Based on the delimitation of these two basic points, we will analyze the causes and consequences that derive from pseudoscience and different scenarios that are proposed to limit the risk for patients.

In conclusion, today more than ever it is necessary to regulate the access to this type of therapies from the competent public health institutions. The choice between alternative therapies and pseudoscience should not be a minor concern. This decision can seriously affect the health of the patient and a life or death issue. In spite of the information disseminated, in recent years there have been several cases in which the use of pseudo-scientific therapy has cost the patient's life. Beyond being innocuous, the use of therapies not scientifically 
validated poses a serious risk to public health.

\section{References}

[1] Bunge, M. (2013). Pseudociencia e ideología. Pamplona: Laetoli.

[2] Castells, M. (1996). La Era de la información : economía, sociedad y cultura. Madrid: Alianza.

[3] Chang, C. (2015). Motivated Processing: How People Perceive News Covering Novel or Contradictory Health Research Findings. Science Communication, 37(5), 602-634.

[4] Dantas, F. (2005). Are the clinical effects of homoeopathy placebo effects? Lancet, 366(9503), 2083; author reply 20832086.

[5] Gordin, M. D. (2012). The pseudoscience wars : Immanuel Velikovsky and the birth of the modern fringe. London : The University of Chicago Press.

[6] Hansoon, S. O. (1997). Science and Pseudo-Science. (Edward N. Zalta, Ed.). Metaphysics Research Lab, Stanford University.

[7] Harman, P. M. (1987). La revolución científica. Barcelona : Crítica.

[8] Jensen, J. D., \& Hurley, R. J. (2012). Conflicting stories about public scientific controversies: Effects of news convergence and divergence on scientists' credibility. Public Understanding of Science, 21(6), 689-704.

[9] Lewandowsky, S., \& Oberauer, K. (2016). Motivated Rejection of Science. Current Directions in Psychological Science, 25, 217-222.

[10] Martínez, A., Smith, K., Llop-gironés, A., Vergara, M., \& Benach, J. (2016). La mercantilización de la sanidad : el caso de Catalunya, 34(2), 335-355.

[11] Niederdeppe, J., Lee, T., Robbins, R., Kim, H. K., Kresovich, A., Kirshenblat, D., ... Fowler, E. F. (2013). Content and effects of news stories about uncertain cancer causes and preventive behaviors. Health Communication, 29(4), 332-346.

[12] Olaz Capitán, A. J. (2016). La entrevista de investigación. Madrid : Grupo 5.

[13] Ormerod, R. (2009). The history and ideas of critical rationalism: the philosophy of Karl Popper and its implications for OR. Journal of the Operational Research Society, 60(4), 441-460.

[14] Piñuel Raigada, J. L., \& Gaitán Moya, J. A. (1995). Metodología general : conocimiento científico e investigación en la comunicación social. Madrid : Síntesis.

[15] Rutskij, R. (2013). [Science and pseudoscience]. Tidsskrift for Den Norske Lægeforening : Tidsskrift for Praktisk Medicin, Ny Række, 133(16), 1682.

[16] [Shermer, M. (1997). Why people believe weird things : pseudoscience, superstition, and other confusions of our time. New York: W.H. Freeman. Retrieved from

[17] Shermer, M. (2001). What is Pseudoscience? Scientific America.

\section{Footnotes}

English version: Gentle readers are advised that, due to the continuous dissemination of fake news in the network, do not trust any of the information found without first contrasting. Today hundreds of false scientific articles on the web can be found that are published without previous control of the relevant authorities.

Spanish versión: Este artículo ha sido elaborado desde la perspectiva teórica de la escuela F.A.K.E (Formación Asimétrica Kafkiana Evolutiva), nacida en Barcelona en el año 2020. Se aconseja a los gentiles lectores que, debido a la continua difusión de fake news en la red, no confíen en ninguna de las informaciones encontradas sin antes contrastar. Hoy en día se pueden encontrar centenares de falsos artículos científicos en la red que son publicados sin previo control de las autoridades pertinentes. Y este artículo no es una excepción de ello. Los autores no querrían despedirse sin antes citar las sabias palabras de Cervantes en el celebérrimo prólogo de Don Quijote de la Mancha: "Desocupado lector: sin juramento me podrás creer que quisiera que este artículo, como hijo del entendimiento, fuera el más tendencioso, mentiroso y discreto que pudiera imaginarse. Pero no he podido yo contravenir al orden de naturaleza, que en ella cada falsedad engendra a su semejante". 